\title{
Pengembangan Website Fakultas Teknik Universitas Hamzanwadi Berbasis Progressive WEB APP (PWA)
}

\author{
Iwan Aslan', Hariman Bahtiar2, Aris Sudianto ${ }^{3}$ \\ 1,3 Program Studi Teknik Informatika, Universitas Hamzanwadi \\ 2 Program Studi Sistem Informasi, Universitas Hamzanwadi \\ *worldfaceofit@gmail.com
}

\begin{abstract}
Abstrak
Website Fakultas Teknik Universitas Hamzanwadi merupakan sebuah media pemberitaan online yang menyediakan informasi seputar Fakultas Teknik Universitas Hamzanwadi secara menyeluruh. Namun, dalam upaya untuk meningkatkan kualitas dalam pengaksesan informasi tersebut, maka website perlu ditingkatkan. Dengan menerapkan teknologi Progressive Web Apps (PWA) diharapkan bisa menjadi solusi bagi permasalahan yang ada. Dengan menerapkan teknologi PWA akan memberikan dampak yang cukup signifikan bagi website Fakultas, bila dibandingkan dengan sebelumnya. Tentu, dengan adanya penerapan teknologi pwa ini proses loading pada website akan jauh lebih ringan, cepat, dan lebih efisiensi waktu serta dalam di buka ketika tidak terhubung ke internet atau ketika ofline.
\end{abstract}

Kata kunci : Website Fakultas Teknik Universitas Hamznawadi, Progressive Web Apps (PWA), ringan, cepat, dan efisiensi waktu.

\begin{abstract}
The Hamzanwadi University Faculty of Engineering website is an online news media that provides comprehensive information about the Hamzanwadi University Faculty of Engineering. However, in an effort to improve the quality of accessing this information, the website needs to be improved. By implementing Progressive Web Apps (PWA) technology, it is hoped that it can be a solution to existing problems. By implementing PWA technology, it will have a significant impact on the Faculty's website, when compared to before. Of course, with the application of PWA technology, the loading process on the website will be much lighter, faster, and more time efficient and open when not connected to the internet or offline.
\end{abstract}

Keywords: Website of the Faculty of Engineering, Hamznawadi University, Progressive Web Apps (PWA), lightweight, fast, and time efficient.

\section{Pendahuluan}

Penggunaan Teknologi Informasi dan Komunikasi belakangan ini sangat besar pengaruhnya dalam berbagai macam aspek kehidupan masyarakat, terutama sekali yang berkaitan dengan masalah penyebaran inforamasi di berbagai media massa yang merupakan salah satu kebutuhan penting bagi masyarakat luas. Penggunaan Teknologi Informasi telah mempengaruhi berbagai kalangan masyarakat mulai dari masyarakat golongan menengah ke atas samapi dengan masyarakat golongan ke bawah. Hal ini disebabkan karena perkembangan teknologi sudah menjadi kebutuhan bagi masyarakat dalam melakukan 
aktivitas kehidupan sehari-hari terlebih dalam mengakses suatu informasi. Salah satu contohnya adalah tersedianya Website Fakultas Teknik Universitas Hamzanwadi yang terletak di Pancor, Lombok Timur.

Fakultas Teknik di bawah naungan Universitas Hamzanwadi, sebagai wadah tempat menimba ilmu. Sebagai wadah tempat pembelajaran bagi Mahasiswa/i tentu sangat berkomitmen untuk selalu meningkatkan kualitas dalam menyediakan informasi yang akan di akses oleh civitas Fakultas. Dalam upaya mencapai hal tersebut tentu kehadiran sebuah sistem informasi sangat diperlukan. Namun, di dalam Website tersebut penulis melihat bahwa teknologi yang digunakan masih seperti Web atau sistem informasi pada umumnya, dimana pengguna tidak bisa mendapatkan akses yang cepat ketika mengunjungi website tersebut walaupun pengguna memiliki koneksi yang cukup, sehingga untuk meningkatkan kualitas ataupun kecepatan yang maksimal maka perlu diterapkan teknologi yang memungkinkan kinerja dari website semakin maksimal. Untuk mencapai hal tersebut, maka perlu penerapan teknologi Progressive Web Apps (PWA), dengan menerapkan teknologi tersebut kecepatan proses loading website ketika diakses akan lebih cepat walaupun dalam kondisi jaringan lemah (low conection). Sehingga, akan memberikan dampak yang cukup signifikan bagi Fakultas Teknik Universitas Hamzanwadi baik bagi civitas khususnya dalam mengakses informasi.

\section{Tinjauan Pustaka}

\subsection{Penelitian Terkait}

- Awal Kurniawan, Intan Sari Areni, Andani Achmad melakukan penelitian yang berjudul "Implementasi Progressive Web Application pada Sistem Monitoring Keluhan Sampah Kota Makassar". Teknologi web sudah mengalami banyak kemajuan. Dimulai dari era web 1.0 yang masih bersifat statis hingga teknologi web yang mampu mengatasi permasalah perangkat keras seperti storage, speech recognition, hingga geolocation. Salah satu teknologi web yang hadir saat ini adalah progressive web application. Penelitian ini bertujuan untuk merancang sebuah sistem yang dapat melakukan proses caching file pada konten website. Sistem menggunakan progressive web application dengan memanfaatkan service worker. Sumber data yang akan dijadikan objek pada penelitian ini adalah data keluhan masyarakat yang berbentuk JSON. Pada penelitian ini digunakan metode eksperimental dalam merancang aplikasi. Data keluhan yang bersumber dari sebuah API (Application Programming Interface) kemudian ditampilkan dalam keadaan jaringan aktif. Selama dalam keadaan jaringan aktif, service 
worker melakukan tugasnya dalam melakukan proses caching. Setelah itu, data yang sudah disimpan bisa diakses pada jaringan tidak aktif. Hasil dari penelitian ini adalah sistem keluhan yang disisipkan service worker mampu melakukan proses caching data hingga 500 data keluhan. Meskipun eksekusi waktu yang dibutuhkan dalam mengakses aplikasi lebih lama karena pemasangan service worker, namun aplikasi yang diakses lebih cepat ketika dalam keadaan offline karena data dimuat dalam cache service worker[1].

- Penelitian yang dilakukan oleh Adriyansah Efendi Noor, Pahrul Irfan yang berjudul "Implementasi Progressive Web Apps (PWA) Menggunakan Laravel Dan Vue.Js Dalam Pembuatan Aplikasi Penyedia Jasa Freelance". Sekolah menengah Kejuruan atau biasa disingkat SMK, merupakan program pemerintah yang dibangun dengan tujuan agar para siswa bisa memiliki keahlian dalam bidang tertentu dan dapat menjadi modal awal bagi mereka dalam mencari kerja. Kurikulum pendidikan yang telah terakreditasi dan banyaknya kegiatan praktik yang diberikan kepada para siswa juga dapat menjamin bahwa lulusan SMK siap untuk memasuki lapangan kerja. Namun dalam dunia kerja saat ini dibutuhkan pekerja yang selain memiliki keterampilan, juga harus memiliki pengalaman kerja. Adanya eventevent yang diadakan oleh pemerintah tentang info Lowongan Pekerjaan pun diadakan hanya beberapa kali dalam setahun sehingga membuat peserta yang mengikutinya semakin banyak dan tingkat pengangguran yang ada di daerah semakin tinggi. Berdasarkan masalah diatas, penulis memberikan sebuah solusi dengan cara membuat "Aplikasi Penyedia Jasa Freelance" yang diharapkan nantinya agar dapat mempertemukan para pekerja dan pencari pekerja[2].

Aris Sudianto melakukan penelitian dengan judul "Penerapan Website Sebagai Sarana Promosi Wisata Budaya pada Kabupaten Lombok Timur". Sistem informasi wisata budaya berbasis web digunakan sebagai alat bantu dalam penyampaian informasi pada wisata dan budaya yang di terdapat di kabupaten lombok timur kepada masyarakat yang ingin mengetahui daerah wisata yang ada di lombok timur sistem,sistem informasi wisata berbasis web merupakn salah satu bentuk media atau sarana promosi wisata budaya di kabupaten lombok timur yang bertujuan untuk menarik minat para wisatawan baik lokal maupun mancanegara untuk berkunjung ke pulau lombok khususnya lombok timur[3]. Penelitian ini diharapkan dapat bermanfaat sebagai media informasi 
dan promosi potensi wisata yang ada dikabupaten lombok timur ,sehingga masyrakat akan lebih mengenal tempat pariwisata daerah yang dikunjungi, selain itu dengan dikenalnya lokasi wiata oleh para wisatawan dapat berimbas pada peningkatan dari segi ekonomi untuk masyarakat sekitar lokasi wisata[4][5].

\subsection{Landasan Teori}

\section{Sistem Informasi}

Sistem Secara Umum, Pengertian Sistem Informasi adalah suatu sistem yang menyediakan informasi untuk manajemen pengambilan keputusan atau kebijakan dan menjalankan operasional dari kombinasi orang-orang, teknologi informasi dan prosedur-prosedur yang terorganisasi. Atau sistem informasi diartikan sebagai kombinasi dari teknologi informasi dan aktivitas orang yang menggunakan teknologi untuk mendukung operasi dan manajemen. Sedangkan dalam arti luas, sistem informasi diartikan sebagai sistem informasi yang sering digunakan menurut kepada interaksi antara orang, proses, algoritmik, data dan teknologi (Simanungkalit 2014)[3].

\section{Website}

Website merupakan sebuah kumpulan halamanhalaman web beserta file-file pendukungnya, seperti file gambar, video, dan file digital lainnya yang disimpan pada sebuah web server yang umumnya dapat diakses melalui internet. Atau dengan kata lain, website adalah sekumpulan folder dan file yang mengandung banyak perintah dan fungsi fungsi tertentu, seperti fungsi tampilan, fungsi menangani penyimpanan data, dsb[3][7]

\section{Progressive Web App (PWA)}

Kurniawan, dkk. (2017) menyatakan bahwa Progressive Web Apps (PWA) adalah sebuah istilah untuk aplikasi berbasis web yang menggunakan teknologi web paling mutakhir. PWA sebenarnya hanyalah aplikasi berbasis web biasa, tapi memanfaatkan fitur perambanan yang modern agar tampil seolah-olah merupakan aplikasi asli. PWA digambarkan sebagai kumpulan dari teknologi, konsep desain dan WEB API (Application Programming Interface) yang bekerja secara bersama untuk memberikan sentuhan aplikasi pada sebuah mobile web. Kurniawan (2018) menjelaskan bahwa "Progressive Web Apps" adalah aplikasi native yang mendukung hybrid secara penuh dan aplikasi ini tidak perlu proses penginstallan terlebih dahulu namun langsung dapat digunakan secara penuh[1].

\section{Flowmap}

Flowmap atau bagan alir adalah bagan yang menunjukkan aliran di dalam program atau prosedur sistem secara logika. Flowmap berfungsi untuk memodelkan masukan, keluaran, proses maupun transaksi dengan menggunakan symbol-simbol tertentu. 
Pembuatan flowmap harus dapat memudahkan pemakai dalam memahami alur dari sistem atau transaksi. Adapun simbol yang digunakan dalam flowmap terlihat sebagai berikut [6][9].

\section{Data Flow Diagram (DFD)}

DFD ini merupakan alat perancangan sistem yang berorientasi pada alur data konsep dekomposisi dapat digunakan untuk penggambaran analisa maupun rancangan sistem yang mudah dikomunikasikan oleh professional sistem kepada pemakai maupun pembuat program[7].

\section{SublimeText}

Sublime Text Editor adalah editor teks untuk berbagai bahasa pemograman termasuk pemograman PHP. Sublime Text Editor merupakan editor text lintas platform dengan Python Application Programming Interface (API). Sublime Text Editor juga mendukung banyak bahasa pemrograman dan bahasa markup, dan fungsinya dapat ditambah dengan plugin, dan Sublime Text Editor tanpa lisensi perangkat lunak [8].

\section{VueJS}

VueJs adalah JavaScript framework yang dikembangkan untuk membangun antarmuka suatu software[9].

\section{Web Server}

Web Server adalah potongan perangkat lunak yang memiliki fungsi sebagai tempat menyimpan dokumen-dokumen web dengan dukungan berbagai protocol web dan lain-lain untuk memproses permintaan client[10].

9. HTML

Hypertext Markup Language (HTML) adalah sebuah bahasa markah yang digunakan untuk membuat sebuah halaman web, menampilkan berbagai informasi di dalam sebuah penjelajah web Internet[11].

\subsection{Tahapan Penelitian}

Sistem yang akan dikembangkan nantinya mampu menjawab segala permasalahan yang ada, diantaranya dapat dilihat pada Tahapan penelitian yang digambarkan di bawah ini :

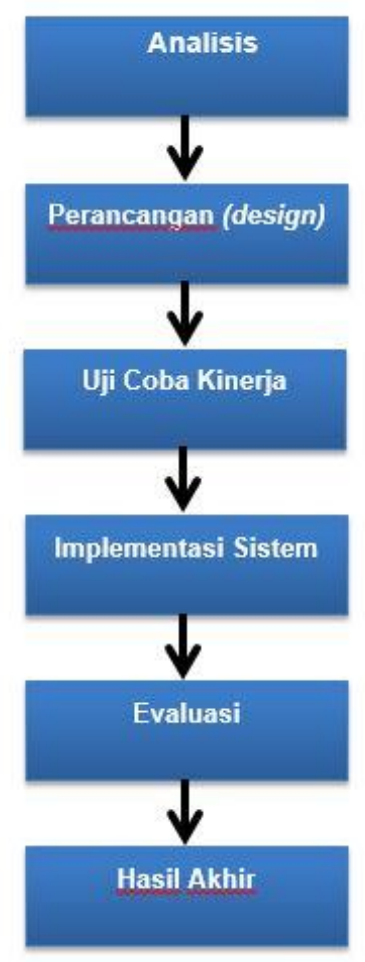

Gambar 1 : Metode Penelitian

Beberapa tahapan Metode yang dilakukan untuk pengembangan website ini adalah antara lain : 


\section{Tahap Analisis}

Melakukan analisis dan pengumpulan data dengan bersumberkan internet dan beberepa referensi jurnal yang bersangkutan tentang bagiamana melakukan pengembangan terhadap suatu website dengan menerepkan teknologi Progressive Web Apps (PWA) pada jurnal yang bersangkutan.

\section{Tahap Perancangan}

Menentukan konsep bagaimana menerapkan teknologi Progressive Web Apps (PWA), serta menentukan list dari menu yang akan di tampilkan pada pengembangan Website.

\section{Tahap Ujicoba}

Melakukan uji coba dan melihat bagaiamana proses ketika sudah menerapkan teknologi Progressive Web Apps (PWA) pada portal dan mendapatkan hasil perbandingan sebelum diterapkan teknologi tersebut.

\section{Tahap Implementasi}

Melakukan penerapan teknologi Progressive Web Apps (PWA) sehingga bisa meningkatkan kinerja dari website atau portal menjadi lebih optimal ketika diakses oleh pengunjung portal.

\section{Evaluasi}

Pada tahapan ini melakukan peyempurnaan dan perbaikan produk berdasarkan hasil ujicoba yang sudah dilakukan sebelum berdasarkan parameter yang sudah ditentukan.

6. Hasil Akhir
Pada bagian ini Portal yang sudah diterapkan teknologi Progressive Web Apps (PWA) sudah dapat di akses oleh pengguna dengan kecepatan proses loading website lebih cepat walaupun koneksi dapat dibilang lambat.

a. Diagram Konteks

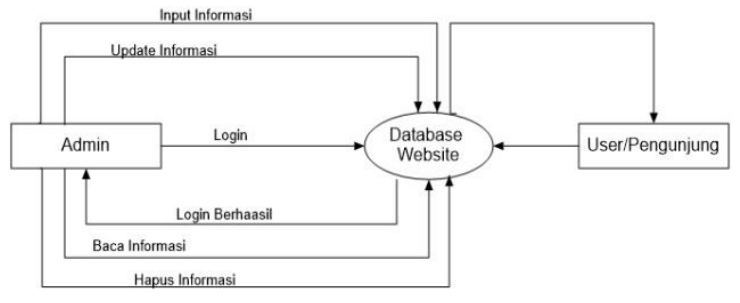

Gambar 1 : Diagram Konteks

\section{Metode Penelitian}

3.1. Metode yang dilakukan pada Pengembangan Website Fakultas Teknik Universitas Hamzanwadi Berbasis PWA.

Berikut beberapa teknik pengumpulan yang digunakan dalam pengumpulan data pada penelitian ini adalah sebagai berikut:

\section{Observasi}

Observasi adalah suatu kegiatan mencari dan mengumpulkan data yang dilakukan dengan pengamatan secara langsung terhadap peristiwa yang behubungan dengan objek penelitan. Dalam hal ini penulis terlibat langsung dalam pengumpulan data dan melihat langsung sistem yang digunakan serta melakukan pencocokan dengan menjadikan beberapa referensi penelitian sebagai paramater yang sesuai dengan judul penelitian. 


\section{Studi Pustaka}

Mengumpulkan informasi yang berhubungan dengan masalah yang diteliti untuk memperoleh data sekunder. Pada bagian ini penulis mengambil beberapa referensi dari beberapa jurnal penelitian dosen yang berkaitan. Dengan melakukan studi pustaka serta melakukan analisis persamaan dari beberapa sumber referensi maka penliti dapat memperoleh landasan teroi yang cukup terkait masalah yang sedang diteliti.

\subsection{Lokasi Penelitian}

Penelitian ini dilakukan dengan mengumpulkan sumber data langsung bertempat di Fakultas Teknik Universitas Hamzanwadi yang beralamat Jalan Professor M Yamin No.35, Pancor, Selong, Kabupaten Lombok Timur, Nusa Tenggara Bar. 83611

\section{Hasil dan Pembahasan}

Setelah melakukan pengembangan dengan melakukan perancangan, website Fakultas Teknik terdiri dari bebapa tampilan dimana masing-masing tampilan/halaman tersebut memeliki fungsi yang berbeda-beda baik dalam penginputan maupun penyimpanan data. Berikut bebrapa gambar user interface yang sudah diimplementaskan sebagai berikut :I
1. Halaman Back-end (admin)

- Halaman Login

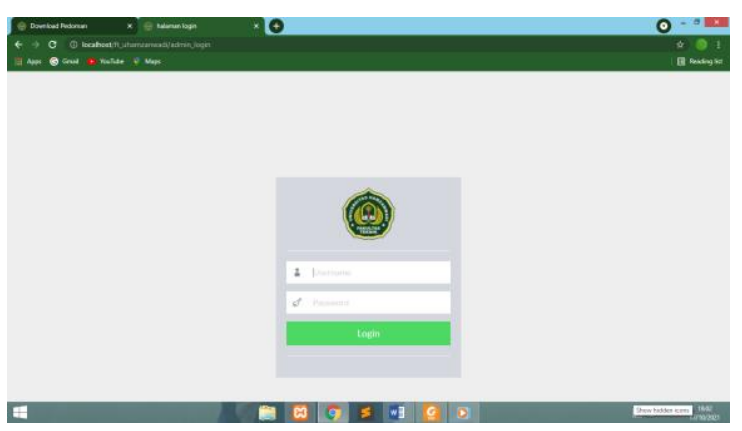

Gambar 3 :Login Admin

Halaman ini akan tampil untuk pertama kalinya setelah admin mengakses link yang digunakan untuk login. Setelah itu, admin perlu melalukan login dengan menggunakan username dan password.

- Halaman Dashboard Admin

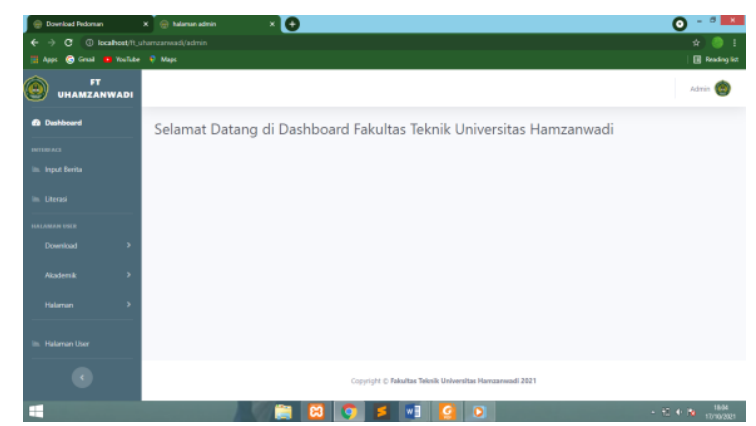

Gambar 4 : Dashboard Admin

Halaman ini akan tampil untuk pertama kalinya setelah admin berhasil masuk dengan menggunakan username dan password tadi. Pada halaman ini admin dapat memilih aksi yang akan dilakukan, seperti input berita ataupun mengubah berita dan iformasi lainnya. 
2. Halaman Front-end (user)

- Halaman User Beranda

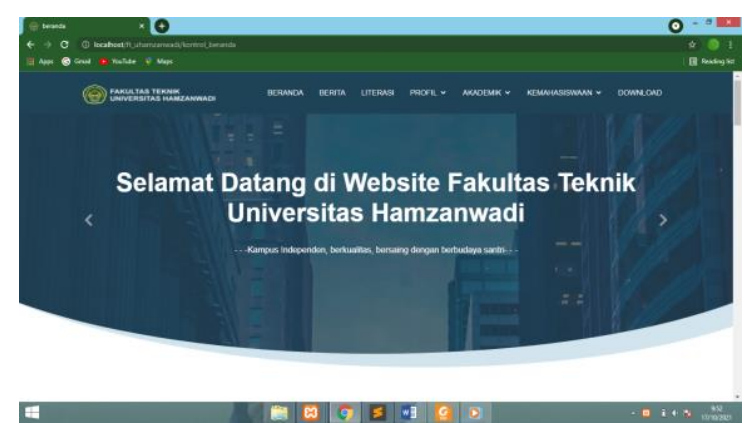

Gambar 5 : Halaman Beranda User

Tampilan beranda adalah tampilan yang pertama kali tampil ketika website di akses oleh user ataupun admin.

Kesimpulan : Berdasarkan pengujian sistem, maka website Fakultas Teknik Universitas Hamzanwadi sudah layak untuk di gunakan.

\section{Kesimpulan}

Berdasarkan penelitan yang dilakukan di Fakultas Teknik Universitas Hamzanwadi, maka penulis menyimpulkan pembahasan yang dapat diambil beberapa kesimpulan yaitu:

1. Sistem informasi di bidang Pendidikan sangatlah penting guna meningkatkan kualitas dan daya saing global bagi pendidikan itu sendiri.

2. Menerapkan Teknologi Progressive Web App (PWA) dapat menignkatkan kinerja pemrosesan dalam sebuah website serta meningkatkan efektifitas Website.
3. Perancangan yang matang dan hati-hati menjadi syarat yang sangat penting keberhasilan pemanfaatan teknologi.

4. Dalam dunia informasi, kecepatan sebuah website dalam memberikan respon bagi pengguna sangatlah penting.

\section{Daftar Pustaka}

[1] A. Kurniawan, I. S. Areni, and A. Achmad, "Implementasi Progressive Web Application pada Sistem Monitoring Keluhan Sampah Kota Makassar," J. Penelit. Enj., vol. 21, no. 2, pp. 34-38, 2018, doi: 10.25042/jpe.112017.05.

[2] A. E. Noor and P. Irfan, "Implementasi Progressive Web Apps (PWA) Menggunakan Laravel Dan Vue.Js dalam Pembuatan Aplikasi Penyedia Jasa Freelance," JTIM J. Teknol. Inf. dan Multimed., vol. 2, no. 3, pp. 174-180, 2020, doi: 10.35746/jtim.v2i3.109.

[3] L. K. W. Sudianto Aris, Nurhidayati, "Penerapan Sistem Informasi Geografis Untuk Pemetaan Bengkel Tambal Ban di Kecamatan Selong Kabupaten Lombok Timur," Infotek J. Inform. dan Teknol., vol. 3, no. 1, pp. 51-57, 2020, doi: 10.1029/2019GH000237.

[4] Arifin, "Penerapan Website Sebagai Sarana Promosi Wisata Budaya pada Kabupaten Lombok Timur," J. Mater. Process. Technol., vol. 1, no. 1, pp. 1-8, 2018.

[5] A. Sudianto and M. Wasil, "Penerapan Sistem Informasi Geografis dalam Pemetaan Sebaran Kasus Gizi Buruk Lombok Timur merupakan salah satu Kabupaten yang berada di Provinsi Nusa Tenggara Barat yang terletak di sebelah Timur Pulau Lombok , Kabupaten Lombok Timur Gizi Buruk Malnutrisi," vol. 4, no. 2, pp. 142-150, 2021.

[6] S. Suhartini, M. Sadali, and Y. Kuspandi 
Putra, "Sistem Informasi Berbasis Web Sma Al- Mukhtariyah Mamben Lauk Berbasis Php Dan Mysql Dengan Framework Codeigniter," Infotek J. Inform. dan Teknol., vol. 3, no. 1, pp. 79-83, 2020, doi: 10.29408/jit.v3i1.1793.

[7] Sudianto Aris, "Penerapan Website Sebagai Sarana Promosi Wisata Budaya pada Kabupaten Lombok Timur," Infotek J. Inform. dan Teknol., vol. 1Sudianto, no. 1, pp. 11-17, 2018.

[8] F. B. Zulmi, "Sistem Pendukung Keputusan Pemilihan Pegawai Berprestasi Pada Badan Kepegawaian Daerah (BKD) Binjai Menggunakan Metode Profile Matching Berbasis Android." 2019.

[9] A. Sudianto and M. Sadali, "Penerapan Aplikasi Berbasis Android Untuk Ternak Ayam Petelur Sebagai Wadah Untuk Menghubungkan Pemilik Modal Dengan Calon Peternak," Infotek J. Inform. dan Teknol., vol. 4, no. 1, pp. 87-95, 2021, doi: 10.29408/jit.v4i1.2999.

[10] Z. Yunizar, "Sistem Informasi Dana Desa Berbasis Web Mobile di Kecamatan Makmur Kabupaten Bireuen," J. Teknol. Terap. Sains 4.0, vol. 1, no. 3, pp. 1-10, 2020.

[11] J. S. Pasaribu, "Penerapan Framework YII pada Pembangunan Sistem PPDB SMP BPPI Baleendah Kabupaten Bandung," J. IIm. Teknol. Terap., vol. 3, no. 2, pp. 154163, 2017.

[12] A. Sudianto and H. Ahmadi, "Rancang Bangun Sistem Informasi Penjualan Sparepart Motor Pada Bengkel Vinensi Motor Berbasis Web Guna Meningkatkan Penjualan dan Promosi Produk," vol. 3, no. 2, pp. 115-122, 2020.

[13] M. Arifin, P. Luthfi Mahendra, and P. Kurnia Handayani, "Implementasi Aplikasi Portal
Rental Mobil Online Berbasis Web," Pros. SNATIF Ke-3, no. 2003, pp. 295-302, 2016.

[14] S. Di, S. M. A. Negeri, and P. Lampung, "(1 (2)," no. 2, pp. 93-109.

[15] v. Afifah and d. Setyantoro, "rancangan sistem pemilihan dan penetapan harga dalam proses pengadaan barang dan jasa logistik berbasis web," j. Ikra-ith inform., vol. 5, no. 2, p. 112, 2021.

[16] Hariman Bahtiar; Muhamad Wasil; Bambang Harianto, "Digitalisasi Karya TGKH. Muhammad Zainuddin Abdul Madjid berbasis mobile sebagai media pembelajaran interaktif untuk pelestarian peninggalan pendiri Nahdlatul Wathan," Infotek J. Inform. dan Teknol., vol. 88, no. 5, pp. 427-434, 2019.

[17] H. Bahtiar, A. E. Sutriadi, M. Djamaluddin, and T. Barat, "Digitalisasi Kitab Nadham Batu Ngompal Karya TGKH . Muhammad Zainuddin Abdul Madjid Berbasis OPF Flipbook Pulau Lombok sebagai salah satu pulau yang mempunyai potensi yang cukup besar untuk dijadikan objek wisata. Dengan keindahan alam dan keanekaragaman," Infotek J. Inform. dan Teknol., vol. 3, no. 2, pp. 1-8, 2020.

[18] H. Bahtiar, M. Djamaluddin, L. M. Samsu, and K. L. Timur, "Digitization of Hizib Nahdlatul Wathan by TGKH . Muhammad Zainuddin Abdul Madjid Based on the OPF Flipbook," IAIC Int. Conf., vol. 3, no. 1, pp. 20-25, 2020.

[19] H. Bahtiar and L. Kerta Wijaya, "Mobile Based Geographic Information System for mapping and data collection Towards 4.0 Industry," J. Phys. Conf. Ser., vol. 1539, no. 1, pp. 0-5, 2020. 